\title{
A Study on Sustainable Development of Grain Production Coping with Regional Drought in China
}

\author{
Fengying Xu, Zhen Chen, Changyou Li, Ce Xu, Jieyu Lu, Yi Ou \\ Key Laboratory of Key Technology on Agricultural Machine and Equipment Ministry of Education, (South \\ China Agricultural University), Guangzhou 510642, P.R. China
}

\begin{abstract}
The sustainable development of grain production is a necessary condition for Chinese rapid economic development, which is directly related to people's livelihood and national security. This paper analyzed the frequent occurrence causes of regional drought in China, emphatically enumerated the North-South imbalance of precipitation distribution in time and space, the excessive tillage and grazing and vegetation damage, the hydro-agricultural infrastructure aging and the rapid urbanization diverted for agricultural water resources, which impact the sustainable development of grain production, then proposed some countermeasures coping with frequently regional drought crisis: strengthen the protection of forest vegetation, the scientific planning of planting structure, and the balance regulation of urban industrial water and grain irrigation water, surface water and ground water and of the water allocation between the administrative region, and solve the discharge of sewage purification and desalination technologies, thus establish an integrated balance system of total supply and regional control of grain irrigation water, so as to continuously perfect the durable and stable supply of grain in China.
\end{abstract}

Index Terms: Grain production; regional drought; sustainable development; water resources; grain irrigation water.

(C) 2011 Published by MECS Publisher. Selection and/or peer review under responsibility of the Research Association of Modern Education and Computer Science.

\section{Introduction}

As the saying going, people regard food as their prime want, food is the most basic material for human life. The sustainable development of grain production is the essential condition for rapid economic development, which is directly related to people's livelihood and national safety [1-2]. William Engdahl In the book "Seeds of Destruction: The Hidden Agenda of Genetic Manipulation" has ever sharply presented that "Control oil and you

* Corresponding author.

E-mail address: xu_fy@scau.edu.cn 
control nations; control food and you control the people." [2]. Because of the large population base in China, the sustainable development of self-sufficiency in grain production has an important social significance. Nowadays, Chinese population is approximately 1.3 billion, it is supposed that the direct and indirect consumption dosage of per-capita were 400-500 kilograms, the requirement of annual grain would reach 5 million tons and it only could be balanced the Chinese grain production [3]. With the increase of urbanization speed, the area of farmland in China continues to decline and it is approaching the red line of the farmland's area that is about 18 billion, plus the frequent occurrence of regional drought, which has a great impact on the sustainable development of Chinese grain production [4]. Grain production volume has fluctuated on the balance line of about 5 million tons for many years. With the increase of population, if China has 1.6 billion people, the requirements of Chinese grain will reach 640-800 million tons [5], the gap between requirement and provision showed that Chinese grain production need rising steadily $30 \%$ to $60 \%$ in our country based on the total grain production at present, which will make a greatly rigid pressure on the existing grain production of our country and make a higher request for the grain unit yield [6].

In present, although there is great progress of in unit yield increasing effect and plants of the grains in china, the potential of sustainable development has been restricted deeply because of the resource environment, especially by the lack of agricultural water resources. From 1980 to now, agricultural water represented in water use in entire country was dropping yearly, huge amounts of farmland water was replaced by the urban industry and water for life and the drought area in agriculture is in accelerating trend [7-8]. Fig.1 showed the contrast of average grain output, arable land and annual average dry area. There is huge loss because of the drought in grains, and it makes a reduction in production of 15 billion to 20 billion kilograms and it accounts for about $5 \%$ in the average production of the whole country.

As the aggravation of global warming, the ecological area of grain farmland worsens deeply such as the lack of irrigation water in grain, the pollution in water getting serious, more and more droughts in different areas and the continuous reduction of production. In present, the areas in droughts in our country reach 0.5 billion mu, is 3 times of that in 50's in last century [8-9]. There are huge pressure in water for irrigation and fighting the droughts in terms of the grain production system of weak foundation. To make sure the sustainable development in grains, to decrease the loss of grain production in drought areas, and to solve the difficult problems in selfsupport and self- provision in the future, we will discuss the causes by the frequently droughts in areas to restrict the sustainable development in grains and give the four safeguard measures which need to be valued in terms of the above causes.

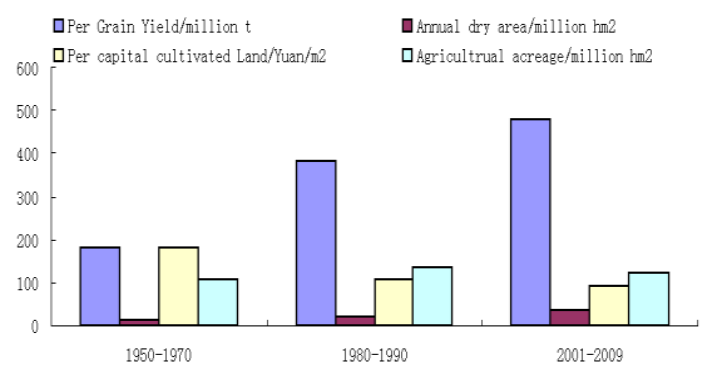

Fig.1 Contrast of annual average grain yield, annual average cultivated area and annual average dry area.

\section{The Cause Analysis of Regional Drought Restricting Grain Production and Sustainable Development}

\section{A. Imbalance of The Temporal and Spatial Distribution of Farmland and Water Recourse}


Our country is a country that has serious regional water shortage problem. Available freshwater and farmland resources space-time distribution is extremely coordination, and inter-annual variability. At present, the amount of the available surface water and the groundwater freshwater is totally to 11,000 billion cubic meters, including groundwater resource for 2000 billion cubic meters. The per-capita water resource is only 800 cubic meters [910]. $70-90 \%$ of our country annual precipitation concentrates in June to September.

The total annual precipitation become varies greatly and the extreme dry climate occurs frequently. The atmospheric circulation, sea-land position and terrain, hypsography and other factors influence the precipitation. China water resources distribution form a pattern that the south is rich and the north is poor. In the Yangtze river basin and the south of its cultivated land only account for the country's cultivated land 38\%, but their water resources account for the national water resources more than $81 \%$. However Huai river basin and its northern region water resources only account for the national water resources $19 \%$, In the northern food planting area whose water and soil resources allocation proportion is very unbalanced, agricultural water is very scarce. More than half of cultivated area half is in arid and semiarid, the water resources per capita is only 300 cubic meters, which is only more than 20-80 cubic meters of the minimum water requirement per mu rice and wheat [11]. Because of the extreme lack of agricultural production of irrigation water resources, food production process is undue dependent on groundwater resource, it has led to the transition of the transition of resources of the groundwater exploitation and result in the over mining in groundwater resources. In present, groundwater resources have been exploit to 80 billion cubic meters and they are represented $40 \%$ of available groundwater resources. This phenomenon leads to many problems such as soil salinization and land collapse etc., and the grain production sustainable development suffers the serious challenges [12-13].

\section{B. The Serious Degeneration of The Regional Ecological Environment in The Rural}

The area of forest per capita is only $1 / 3$ while grass area per capita is $1 / 2$ in our country of the average level in the world. In recent years, because of the over logging, cultivation and herding, deforestation, the grassland and forest in our country has been roughly destroyed, it aggravates the land load and destroys the native vegetation in agricultural ecological area. Currently, there are $440 \mathrm{khm}^{2}$ woodland being transferred to non-woodland in our country every year, $1654 \mathrm{khm}^{2}$ forestland transfer to non-forest land, shrubbery and open forest. The degeneration of lawn is about 2 million hectare, the area of degeneration reaches up to $85 \%$ [9-10]. The over destroy of the native vegetation lead to the declining in natural water storage and regulation ability noticeably. It also changes the conditions of raining in microclimate in areas and the self-restraint ability of vegetation surface is decreasing. What's more, the drought disaster in areas takes place frequently and heavily and it forms a vicious circle. The water loss and soil erosion is more and more heavily, as the area of it come to 3.56 million square kilometer, it represents $37 \%$ of nation total areas and the soil erosion is about 5 billion tons every year while the degeneration rate of arable land is over $40 \%[9,12]$. The ecological imbalance in huge acreage and soil erosion has worsened the ecological environment in rural areas obviously and it may accelerate the desertification eventually.

In recent years, over exploit in lakes and wetlands to supply the lacking grain arable land has worsen the ecological environment in grain production areas. The lakes and wetlands are storehouse of water in river basins; they take the responses of storing and divulge rivers, adjusting the balance of discharge of stream in river basins, and to achieve the irrigation and controlling flood in grain production. Because of the inadequacy exploit and farming, the lakes and wetlands have degenerated totally now. From the establish of our country, there were more than one third lakes put under the plough, and it reached more than 13 thousand square hectares and about 1000 lakes died out due to the exploit. The sluice volume of lakes exploit has decreased more than 50 billion cubic meter, it is as 1.3 times as the whole sluice volume of five potable water lakes while as 5.8 times as storage capacity of The Three Yangtze River Gorges. The decline of storage capacity in natural lakes decreases the ability of drought storage and adjustment and it also increases the pressure and costs of rural artificial water conservancy facilities [15-16]. 


\section{The Weakness of Irrigation and Regulation Capacity of farmland water conservancy works}

Water conservancy is always called "the life vein of grain production". In China, rural infrastructure facilities on water conservancy have lacked updating maintenance for years, which resulted in poor ability at combating drought. In recent years, more funds were put into the water conservancy, but as they were chiefly used in some economical project construction such as the hydroelectricity, it was still a seriously inadequate input for the rural infrastructure facilities repairing and replenishing. Currently, about 55\% of cultivated lands don't have irrigation facilities yet in China, and some irrigation facilities, which are being in use, were mostly built in the 1950s-1960s. Being restricted by economic and technological conditions at that time, some irrigation projects were low standard and with insufficient supporting [17]. After several decades of running, because of long time soil erosion and loss of large-scale dredging, many reservoirs and irrigations have already been aged, gross disrepair, heavy silting, pervious and overgrown. A marked drop in irrigation ability of agricultural water conservancy facilities greatly influenced the drought-relief measures for grain production under the frequent area drought disaster.

\section{Occupancy of Urban Industrial and Living Water to The Agricultural Irrigation Water}

With the rapid development of China economy, the process of urbanization was changing up and now it has been up to $40 \%$. Due to the consistently enhanced urbanization level, the urban industrial and living water consumption increased sharply, and lots of agricultural water was occupied by the various ways. From 1980 to 2004 , including the sharing groundwater usage, the agricultural water could only keep within 350 billion cubic meters for years. The proportion of agricultural water demand has decreased from $80.4 \%$ in 1980 to $66.4 \%$ in $2004 \mathrm{~g}$ [17-18]. Compared to the remarked drop of the agricultural consumption rate, urban industrial and living water consumption have significantly increased 3.3 times, as shown in Fig. 2. While urban industrial and living water consumption increased sharply, it brought enormous quantities of drainage and sewage. Every year, the raw sewage from city or industrial and mining enterprises amounted to 30-40 billion cube meters. The less cleaned and treated sewage has not only polluted 20\%-30\% water bodies of seven great rivers and five great lakes seriously, but decreased the quantity and quality of agricultural irrigation water and aggravated the already serious lack of water resource. In China, the existing grain production has been appearing seriously in an unfavorable condition that lacked technology and competed badly in water resource using. In the presence of the continuous exploding area drought, the whole society has already paid dearly for it.

\section{Solutions}

\section{A. Spatial Allocation and Management of Water Resources}

After years of the policy support, the yield per unit increasing technique and the application of water-saving irrigation in our country's grain production has been got a large achievement. However, there still exist some shortages, such as the unmatched relationship between the responsibility and the benefit of space-allocation, the inadequate standards of the water resources' utilization, and the uncertain management of country's laws and regulations, and so on [18-19]. These problems have been hanging by governments at all levels, scientists and technicians for the past many years. The uninterrupted exploding of regional droughts has intensified the difficulties of grain irrigation water space-allocation and management, which became bottleneck for the sustainable development of country's grain production. In order to ensure the sustainable development of grain production, applications of irrigation water resource should be reformed: planning and dispatching the surface and ground water resources scientifically; allocating the municipal water, industrial water and agricultural water reasonably. And most importantly, focusing on tackling the shortage of water for resource in the north area and water for quality in the south: encouraging economizing water; increasing coefficient of the repeated cycle utilization of municipal water and industrial water; increasing the proportion of the water pollution purified 
treatment and utilization of seawater desalinization to guarantee the quantity and quality of agricultural water resource.

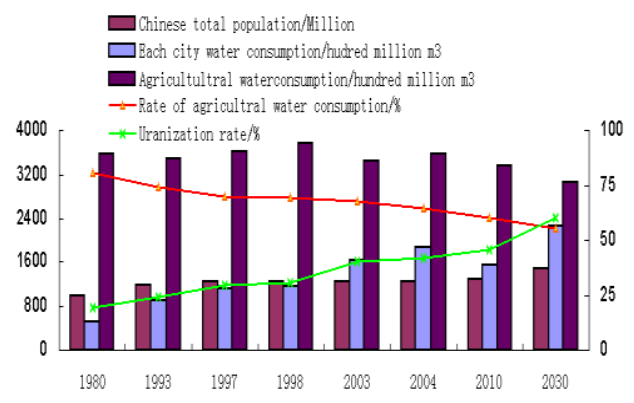

Fig. 2 Contrast between urban industrial and living water and agricultural irrigation water.

\section{B. Vigorous Recondition of Rural Water Conservancy Facilities}

To solve the regional arid, the rural water conservancy facilities, which is what grain production depend on, should be put into much favorable inputs. Designing, planning and maintaining the rural conservancy facilities already had reasonably through the power of country, local governments, enterprises and scientific research, and then gathering manpower and material resources to dredge slit and refit facilities in villages every three or five years. Digging deep reservoirs, dredging water channel and irrigation channel; constructing underground watersaving system in arid and semi-arid area, updating and replenishing underground water system in time to form a full-control circle system, thus the comprehensive water storage and transfusion capability of natural waters and artificial water conservancy facilities can be promoted. Based on above, constantly strengthening the protection of the forest and lawn vegetation, resuming the original lakes and marshes, protecting the regional ecological environment and decreasing the fees of artificial water conservancy facilities.

\section{Development of The Water Saving Irrigation Agriculture and Processing Technique}

Developing the water-saving irrigation technique is an important way to solve the shortage of irrigation water when the droughts come. It should actively transform the irrigation from extensive type to intensive type in grain production, and then combine with science and technology to develop comprehensive water-saving technique to increase the coefficient of agricultural irrigation water utilization from 0.3-0.4 to 0.5-0.6 and coefficient of natural precipitation to $10 \%-30 \%$ [20-23]. It can greatly elevate the grain production space. Nowadays, under the background of lacking capital and technique, household contract in our country is in need of immediate helps and demonstrations from governments and enterprises to lower the investment risks in the application of water-saving technique.

\section{Forecast and Guidance of The Grain Planting Construction on Solving The Regional Drought}

Lower technological level and lagging science and technology are the characteristics of our country's rural grain production. Farmers are more at the mercy of the forces of nature [24-25]. However, because the capability of weather predicting is weak, it's relatively blind for them to choose the grain planting construction. In order to avoid the large impact caused by the regional arid, in the pre-production, the research powers from multidepartments can be concentrated to make forecasts and guidance on the construction. By concentrating the scientific and technological advantages of state scientific research units, meteorological department, hydraulic monitoring and agricultural department efficiently, it can predict and guide farmers to adjust the planting construction. In times of regional drought, introducing the drought resistance crop not only can guarantees the total supply of grain production, but also adjust the variety and the structure of the grain supply. They all help to achieve the sustainable development with the multi-variety grains condition. 


\section{Conclusions}

Based on our growing population, the problem solution of self-sufficiency and stable of grain supply is the important content of public security and persistent development. There are many reasons that result in frequent droughts in regions and huge reductions in grains such as temporal-spatial distribution imbalance in the precipitation from the south to north, over farming and grazing and damage in vegetations, the aging and lifting silt of agricultural water conservancy works and the rapid development of urbanization. In this situation, it produces enormous pressure in the sustainable development in grains production and becomes the most bottleneck problem of the social stability and rapid development in our country. Facing the situation of poor agricultural technology and capital, frequent regional droughts as well as weak grain production, it is need to use the domestic recourse, synthesize various techniques; solve the problem of regional frequent drought; protect the forest and vegetation; adjust the structure of the plant; balance the distribution of industrial water, irrigation water, surface water, underground water resources and the administrative regional water; improve the level of sewage purification and sea water desalination engineering technology and make our country strengthen national sustainable grain production ability when the regional drought happen. This is an arduous and urgent project, and it demands values from all circles and practices to be prefect gradually.

\section{Acknowledgment}

This work is supported by NSFC Grant \#31071583 to F.Y.XU.

\section{References}

[1] Li Yue, E Liu. "Food tsunami" to alert Chinese food security. China National Conditions and Strength. 2009, no.1, pp.8-11 (in Chinese).

[2] Frederick William Engdahl. The Environmental Food Crisis, Intellectual Property Right Press. 2009.

[3] Yuemin Hu. China's policy options of food security for 1.3 billion population, Popular Tribune. 2006, no.1, pp.28-30 (in Chinese).

[4] Zhiming Feng, Baoqin Liu, Yanzhao Yang. A Study of the Changing Trend of Chinese Cultivated Land Amount and Data Reconstructing: 1949-2003.Journal of Natural Resources. 2005,no.1, pp.35-42.

[5] China Statistical Yearbook 2009. China Statistical Publishing House. 2009.

[6] Hongbing Lai. The output volatility and structural analysis of Chinese grain. Journal of Agrotechnical Economics. 2009, no.5, pp.91-96 (in Chinese).

[7] Jun Wang. Utilizable Precipitation Variations and Its Effects on Runoff in the Upper Reaches of the Yellow River Since 1986. Journal of Irrigation and Drainage. 2009, no.4, pp.107-110.

[8] Dalu Fan. Strategy for China's Grain Security in The 21'St Century Based on The Reality of Shortage In Water Resources. Journal of Southwest Agricultural University. 2000, Vol.22, no.3, pp.273-277.

[9] Ai Wang, Lianxi Sheng, Ke Li.et al. Analysis of present situation of water resources and countermeasures for sustainble development in China. Journal of Water Resources and Water Engineering. 2008, Vol.19, no.3, pp.10-14.

[10]Xuefeng Wang, Zhonging Wang, Shujun Zhang.et al. The Stage Division and Characteristic Analysis of Water Use. Journal of Irrigation and Drainage, 2009, Vol.27, no.5, pp.25-29.

[11]Huiyan Gao. Research on Optimization Model for Cropping Structure and Agricultural Water Resources in Well Irrigation Area in North China Plain, Agricultural University of Hebei, 2005. 
[12]Xiangfu Li, Shaoli Wang, Shuxing Fang. et al. Study on the Movement and Controlling of Soil Salts in Yinbei Region. Irrigation and Drainage, 2001, no.3, pp.41-44.

[13] Yushun Zhang, Guoqiang Pan. Irrigation Water Quota for Staple Crops in Henan. Journal of Irrigation and Drainage, 2009, no.5, pp.67-69.

[14] Yuejin Peng. Urbanization impact on water demand. 2002 conference proceedings of water resources and water environment carrying capacity. 2002.Weihai in Shan dong province (in Chinese).

[15]Zhiguang Li, Current condition and dynamic changes of soil erosion in China. China Water Resources, 2009, no.7, pp.8-11.

[16]Chunman Zhang, Peiqing Liu, Hailei Bu. Mathematical Model of Non-steady Water-sand Movable Bed of Sedimentation Reservoir. Journal of Irrigation and Drainage. 2009, Vol.28, no.4, pp.96-99.

[17]Keshan Peng. Plagued the 21st century economic development in China's water problems. Social Science Front.1999, no.1 (in Chinese).

[18]Dadao Lu, Danian Ye, Shimou Yao. Comprehensive measures to be adopted for curbing the aggressive style and space out of control trend on urbanization. Science News, 2007, no.8, pp.4-9 (in Chinese).

[19]Jiabin Lin, Water Resources Management Structure in Japan. China Water Kesources. 2002, no.10, pp.160163.

[20]Xiangzhen Chen, Exploring new finance mechanism for developing irrigation and drainage \& water supply facilities in Fujian Province. China Water Resources, 2008, no.17, pp.34-35.

[21]Hongyuan Fang, Shengwei Gan, Yingying Yu. Regional drought characteristics in China and some countermeasures. Advances In Science and Technology of Water Resources. 2005,Vol.25, no.5, pp.16-19.

[22]Tianxiang Zheng, Xiangru Tang, Xiwen Luo. Effect of Water-saving Irrigation on the Yield Formation of Precision Hill-direct-seeding Rice [J]. Journal of Irrigation and Drainage, 2009, no.5, pp.99-101.

[23]Di Xu, Shihong Gong. Technical supporting system for water saving orientated rehabilitation of large irrigation districts. Journal of Hydraulic Engineering, 2007,Vol.38, no.7, pp.806-811.

[24]Zhang Yuan, Yuexian Xu, Aijun Liu. Recent Changes of the Planting Structure of Cash Crops in China. Review of China Agricultural Science and Technology, 2005, Vol.7, no.5, pp.39-45.

[25]Xiling Zhao, Hao Feng, Pute Wu. Research Progress and R \& D Focus of Modern Rainwater Harvesting Technology. Journal of Irrigation and Drainage, 2009, Vol.28, no.4, pp.1-5. 